\title{
Structure Determination of Donwilhelmsite by Electron Diffraction Tomography
}

Mariana Klementova ${ }^{1}$, Lukas Palatinus ${ }^{1}$, Jörg Fritz ${ }^{2}$, Ansgar Greshake ${ }^{3}$, Richard Wirth ${ }^{4}$, Vera Assis Fernandes $^{3,5}$ and Ludovic Ferrière ${ }^{6}$

1. Institute of Physics of the Czech Academy of Sciences, Prague, Czechia.

2. Saalbau Weltraum Projekt, Heppenheim, Germany.

3. Museum für Naturkunde Berlin, Berlin, Germany.

4. Helmholtz-Zentrum Potsdam - Deutsche GeoForschungsZentrum, Potsdam, Germany.

5. University of Manchester, Williamson Building, Manchester, UK.

6. Natural History Museum, Vienna, Austria.

* Corresponding author: klemari@fzu.cz

Calcium aluminium silicon oxide (CAS) phase, the new mineral "Donwilhelmsite" [1], formed in shock melt pockets in the lunar meteorite Oued Awlitis 001. This meteorite was found on January 15, 2014, in the Western Sahara $\left(25.954^{\circ} \mathrm{N}, 12.493^{\circ} \mathrm{W}\right)$ as two individual stones totaling $432.5 \mathrm{~g}$. The meteorite is classified as an anorthositic lunar melt rock [2]. Shock melt pockets $100 \mu \mathrm{m}$ in size of roughly anorthitic chemical composition contain bundles of up to $20 \mu \mathrm{m}$ long and less than $1 \mu \mathrm{m}$ wide needle-shaped crystals (Fig. 1). The acicular habit and the very small size of these phases reflect rapid growth of the crystals during elevated shock pressures in less than tens of microseconds. In high-contrast BSE image, the acicular crystals appear slightly brighter and surrounded by a comparatively darker halo when compared with the adjacent anorthitic shock melt. This reflects a relative $\mathrm{SiO}_{2}$ enrichment in the halo and relative $\mathrm{SiO}_{2}$ depletion in the denser, high-pressure phase.

A lamella was cut out of the thick section NHMV-O104 with a focused ion beam (FIB) to study the structure of the needle-like crystals. It was investigated by Precession Electron Diffraction Tomography (PEDT) on a Philips CM 120 (LaB6, 120kV) equipped with a NanoMEGAS precession unit DigiStar and an Olympus SIS CCD camera Veleta (2048x2048px). The crystal was sequentially tilted by the step of 1 deg. from -50 to +50 deg., and at every tilt step a precession diffraction pattern in micro-diffraction mode was acquired using a precession angle of $1 \mathrm{deg}$. The data were processed in the PETS software. Structure solution and refinement were performed in the computing system Jana2006. The structure was solved by the charge flipping algorithm using the program Superflip, and refined using dynamical approach [3].

Eight datasets were collected with average lattice parameters $a=5.44(1) \AA, c=12.76(3) \AA$, space group $\mathrm{P6}_{3} / \mathrm{mmc}$. The structure is identical to the one of synthetic crystals experimentally produced at pressures of $>15 \mathrm{GPa}$ and temperatures of $>1550 \mathrm{~K}$ by Gautron et al. [4]. The structure is composed of M1 octahedral sheets that contain $\mathrm{Al}$ and $\mathrm{Si}$ (Fig. 2). These are intercalated with two M2-octahedra occupied by $\mathrm{Al}$, one larger site occupied by Ca coordinated by 12 oxygen atoms, and two Al-tetrahedra with $50 \%$ occupancy. The structure was refined dynamically to $R l(o b s)=8.98 \%$. The chemical composition derived from the structure model is $\mathrm{CaAl}_{4} \mathrm{Si}_{2} \mathrm{O}_{11}$, which is in good agreement with chemical composition of $\mathrm{Ca}_{1.02} \mathrm{Al}_{3.92} \mathrm{Si}_{2.06} \mathrm{O}_{11}$ obtained experimentally [5].

\section{References:}

[1] J Fritz et al., European Journal of Mineralogy 31 (2019), p. 201.

[2] A Ruzicka et al., Meteoritics \& Planetary Science 52 (2017), p. 1014. 
[3] L Palatinus et al., Acta Crystallogr. A 71 (2015), p. 235.

[4] L Gautron et al., Physics and Chemistry of Minerals 27 (1999), p. 47.

[5] The authors acknowledge funding from the Czech Ministry of Education, Youth and Sports (project LM2015087).

(a)

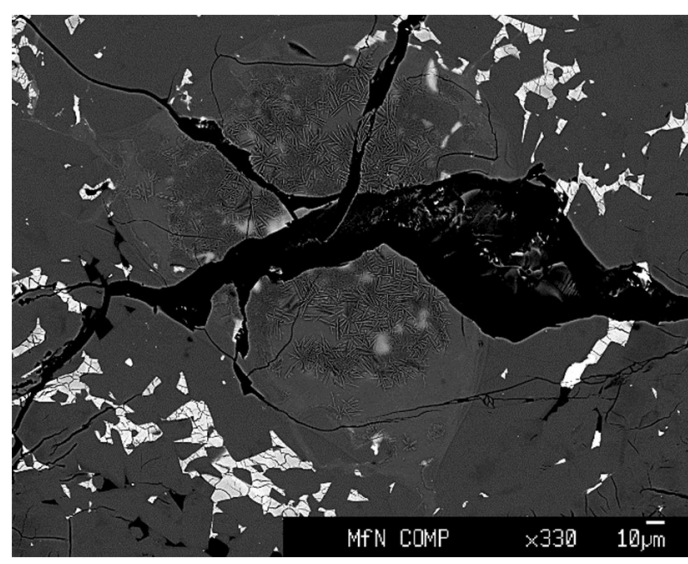

(b)

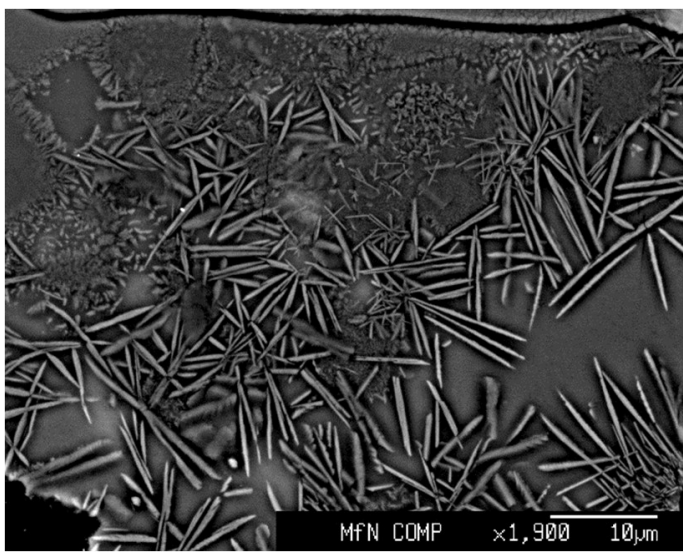

Figure 1. Backscattered-electron (BSE) images of a polished and carbon coated thick section of Oued Awlitis 001. (a) shock melt pocket, (b) needle-like crystals of Donwilhelmsite.

(a)

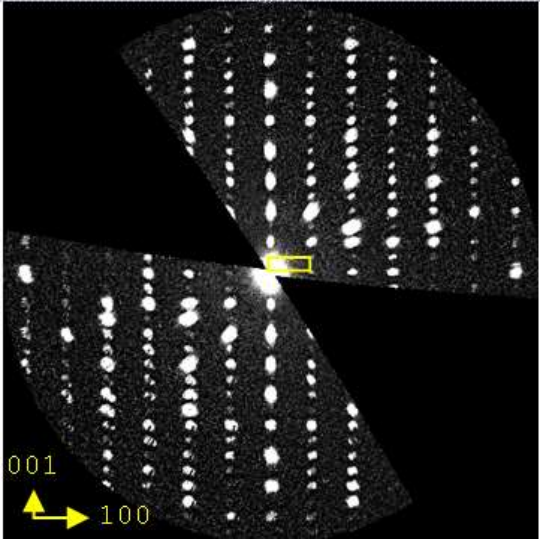

(c)

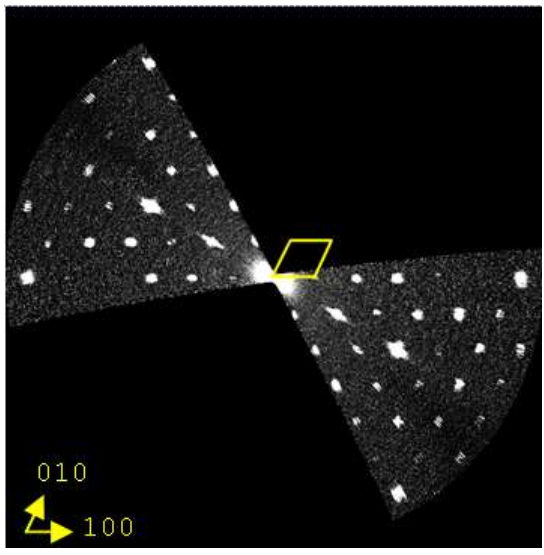

(b)
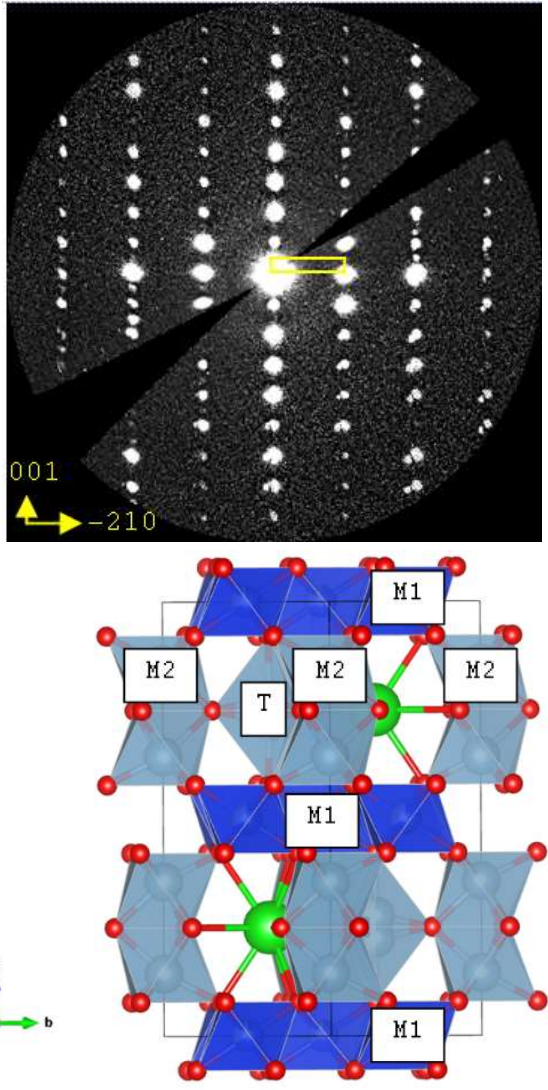

Figure 2. PEDT experiment. Reciprocal space sections (a,b,c). Structure of Donwilhelmsite (d). 